\title{
The Effect of Ethanol Extract of Punica granatum Linn. Leaves on Lipid Profiles of Dyslipidemic Rat
}

\author{
Neng Fisheri Kurniati*, Afrillia Nuryanti Garmana, Lia Nurul Sakinah \\ Department of Pharmacology-Clinical Pharmacy, School of Pharmacy, Institut Teknologi Bandung, Bandung, Indonesia
}

\begin{abstract}
It has been reported that peel of Punica granatum has antidyslipidemic activity. The aim of this research was to investigate the antidyslipidemic activity of Punica granatum leaf. The dried Punica granatum leaves were extracted with $96 \%$ ethanol. Rats were divided into several groups, which were normal, positive control, simvastatin at a dose of $10 \mathrm{mg} / \mathrm{kg}$ bw as reference group, and Punica granatum extract at a dose of $100 \mathrm{mg} / \mathrm{kg}$. Before treatment, male Wistar rats were fed with high cholesterol chow for 3 months, and then plant extract was given for 4 weeks. Blood samples were collected at week $0,12,14$, and 16 to measure the levels of total cholesterol, high-density lipoprotein (HDL)-cholesterol, low-density lipoprotein (LDL)-cholesterol, and triglyceride. Furthermore, at the last day of extract treatment, the aorta was isolated and haematoxylin-eosin stained. Administration of ethanol leaf extract of Punica granatum at a dose of $100 \mathrm{mg} / \mathrm{kg}$ for 2 weeks significantly reduced the total cholesterol and LDL-cholesterol levels up to $27.6 \%$ and $34.79 \%$, respectively, compared to positive control group. After 4 weeks of extract treatment, the reduction of total cholesterol and LDL-cholesterol level were up to $59.9 \%$ and $75.05 \%$, respectively. There was no effect of extract on HDL-cholesterol and triglyceride level. Furthermore, histological study showed that ethanol extract of $P$. granatum reduced aortic wall thickness significantly compared to untreated group. Punica granatum leaf is potential to be developed as an antidyslipidemic drug.
\end{abstract}

Keywords: Punica granatum; ethanol extract; dyslipidemia; hypercholesterolemia; rat

*corresponding author

Email: nfkurniati@fa.itb.ac.id

\section{INTRODUCTION}

Dyslipidemia is a condition of metabolic syndrome disorder which is characterized by increased levels of total cholesterol, LDL, triglycerides, apolipoprotein (apo) B, and decreased levels of HDL. It has been reported that low HDL levels, high triglycerides, and cholesterol levels have a significant and independent relationship to myocardial infarction or stroke (Kolovou et al., 2005). Therefore, dyslipidemia has become a risk factor for various cardiovascular diseases such as atherosclerosis, coronary artery disease, myocardial infarction, and hypertension.

The prevalence of dyslipidemia is very high in Indonesia. Based on Indonesian Heart Association (PERKI) (National Institute of Health Research and Development, Ministry of Health, Republic of Indonesia, 2013), Nangroe Aceh, West Sumatra, Bangka Belitung, and Riau Islands in Indonesia have a prevalence of more than $50 \%$. Furthermore, Indonesia Basic Health Research (Riskesdas) 2013 data shows that the prevalence of abnormal cholesterol, HDL, LDL, and triglyceride levels at age more than 15 years subject in Indonesia were $35.9 \%, 22.9 \%, 60.3 \%$, and $13 \%$, respectively.
Currently, synthetic drugs are used to treat dyslipidemia if life style modification is not successful. However, high side effects are still the major problem for synthetic. This condition has prompted the need for a natural product that can be used as a dietary supplement to treat or even prevent the development of dyslipidemia.

Pomegranate (Punica granatum Linn.) has been known and considered sacred in some countries. Empirically, the whole part of the pomegranate plant is often used by communities to treat a variety of diseases. Many researchers discovered that pomegranate flower extracts can overcome the condition of hyperglycemia in type II diabetes and obesity (Li et al., 2005; Huang et al., 2005; Jafri et al., 2000; Bhaskar \&Kumar, 2012). Concentrated pomegranate fruit juice can improve lipid profiles in diabetic patients with hyperlipidemia (Esmaillzadeh et al., 2004). In addition, pomegranate fruit juice may slow the oxidation of cholesterol by up to half, and lowered the LDL level (Abaas et al., 2014). Furthermore, pomegranate leaves have been reported to have antihyperglycemic and antihyperlipidemic activity in streptozotocin-induced diabetic rats (Patel et al., 2014). However, the antihyperlipidemic activity of pomegranate leaves has not been fully explored 
using dyslipidemic rat model. Therefore, in this study, antidyslipidemia of pomegranate leaves will be studied using dyslipidemic rat model.

\section{METHODS}

\section{Materials}

The following materials were used in this study: highcholesterol chow $10 \mathrm{~kg}$ (20 pieces of chicken liver, 1 $\mathrm{kg}$ of cow fat, $1 \mathrm{~kg}$ of goat fat, 75 quail eggs, 20 duck eggs, $3 \mathrm{~kg}$ of wheat flour and $2 \mathrm{~kg}$ of corn flour), normal chow, cholic acid, pure cholesterol, propylthiouracil (PTU), vegetable oil, aquadest, $\mathrm{NaCl} 0.9 \%$ solution and CMC-sodium. The chemicals used were ethanol, xylol, formaldehyde, paraffin wax, haematoxylin, and eosin (Merck, Germany). Total cholesterol kit, HDL kit, and triglyceride kit was supplied by PT. Rajawali Nusindo, Jakarta, Indonesia.

\section{Test Animals}

The test animals were 20 male Wistar rats aged 10-12 weeks and weighing 200-350 g. The animals were obtained from the Animal Laboratory of School of Pharmacy, Bandung Institute of Technology. All animal experimental protocols have been approved by the Institutional Animal Ethics Committee (IAEC) in accordance with the Committee's guidelines for the Objective of Supervision and Control of Animal Experiments (No. 05/KEPHP-ITB/2016).

The test animals were placed in cages under suitable environments based on animal testing standards. There were four groups consisting of five rats each. Group one was the normal group that was fed with normal chow, without any extract treatment. While group two (positive control group), three and four were fed with high cholesterol chow for 12 weeks to develop dyslipidemic rats. Moreover, for group three consisted of dyslipidemic rats that were treated with simvastatin as a reference drug. Furthermore, group four were treated with $P$. granatum leaf extract at dose of $100 \mathrm{mg} / \mathrm{kg}$ bw.

\section{Antidyslipidemic Rat Model}

Dyslipidemia was induced in the animals through the oral administration of a high-cholesterol diet and water ad libitum, as well as PTU, pure cholesterol, and cholic acid. PTU $12.5 \mathrm{mg} / \mathrm{kg}$ bw/day was suspended in $0.3 \%$ CMC-Na with aquadest as the solvent. Cholic acid 200 $\mathrm{mg} / \mathrm{kg}$ bw/day and pure cholesterol $100 \mathrm{mg} / \mathrm{kg} \mathrm{bw} /$ day were dissolved in vegetable oil. PTU, cholic acid and pure cholesterol were administered orally to the rats for 5 consecutive days each week. The high-cholesterol feed composition was prepared from 20 pieces of chicken livers, $1 \mathrm{~kg}$ of cow fat, $1 \mathrm{~kg}$ of goat fat, 75 quail eggs, 20 duck eggs, $3 \mathrm{~kg}$ of wheat flour, and $2 \mathrm{~kg}$ of corn flour. Cholesterol-rich feed was administered daily for
12 weeks. Afterward, simvastatin and $P$. granatum leaf extract were given daily for 4 weeks (Nurfatwa, 2016).

\section{Collection of Rat Blood}

Rat blood was collected for the evaluation of lipid profile. Rats were put inside restriner and then blood was collected through lateral venous blood vessels in the rat tails. A total of $0.3 \mathrm{~mL}$ of blood was collected into Eppendorf tubes and centrifuged for $5 \mathrm{~min}$ at 10,000 rpm. After centrifugation, the serum was collected and stored at $-20{ }^{\circ} \mathrm{C}$. Lipid profile analysis included the measurement of total cholesterol, triglycerides, High-density lipoprotein (HDL)-cholesterol, and Lowdensity lipoprotein (LDL)-cholesterol (Safitri, 2016). Total cholesterol of serum collected at before induction, 12 weeks after induction, and every 2 weeks during treatment were measured. While for the other lipid profiles, measurements were done for serum collected at week 2 and 4 of simvastatin or extract treatment.

\section{Quantification of Lipid Markers}

Commercially available kits were used to measure the levels of total cholesterol, triglycerides, and HDL according to the manufacturer's instructions. All kits were purchased from PT. Rajawali Nusindo, Jakarta, Indonesia. While for LDL cholesterol, the level was determined using the Friedewald equation as follows (Sukandar, 2016):

$$
\text { LDL }=\text { Total Cholesterol }-\mathrm{HDL}-(\text { Triglyceride } / 5)
$$

\section{Aorta Histology}

The test animals were sacrificed using $\mathrm{CO}_{2}$, then heart and aorta of rats were dissected and isolated for histology. The aorta was soaked in buffered formalin for 1 week. The aorta then was immersed in a container which contains $70 \%$ ethanol, $80 \%$ ethanol, $90 \%$ ethanol, $95 \%$ ethanol, and absolute ethanol respectively for 4 hours. Furthermore, the aorta was immersed in xylol in 3 different containers each for 1 hour to remove residual alcohol from the aorta. Paraffin in solid form was further heated at temperature of $60-65^{\circ} \mathrm{C}$ until liquid and the aorta then was blocked with paraffin. Next, paraffinized aorta was sliced using a microtome with a thickness of 3 $\mu \mathrm{m}$ and placed on the object glass.

\section{Haematoxylin-Eosin Staining}

The object glass that has been filled with pieces of the aorta was put into containers containing xylol, absolute ethanol, 95\% ethanol, 90\% ethanol, 80\% ethanol, and $70 \%$ ethanol for 2 minutes to remove paraffin. The object glass was then washed with clean water to remove alcohol and put in a container filled with hematoxylin dye for 15 minutes. Furthermore, it washed again to remove any residual haematoxylin and put into the container which contains eosin dye for 2 minutes. Then, 


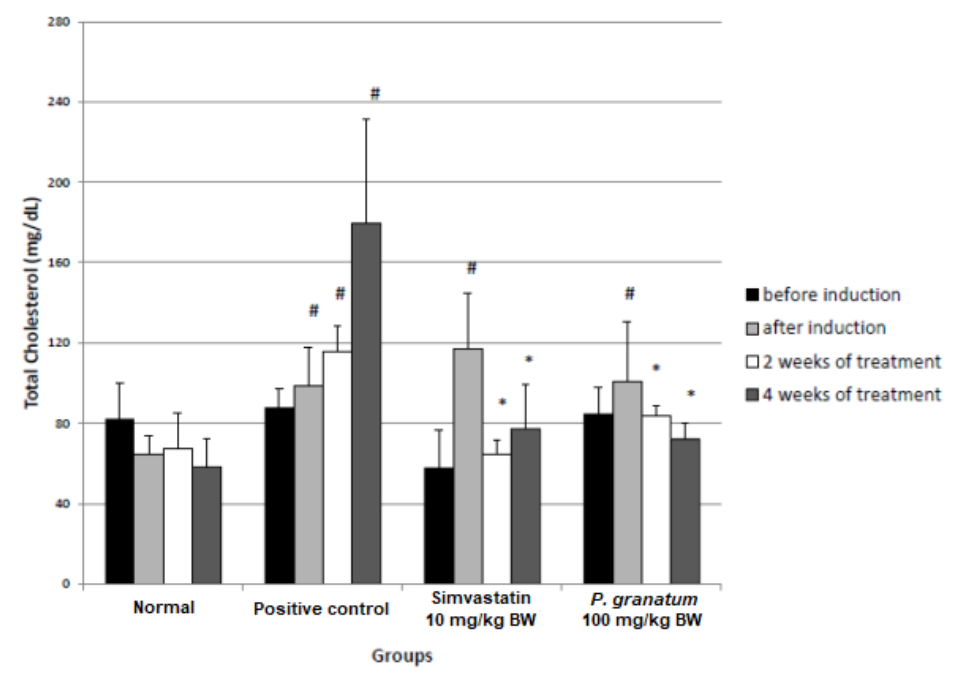

Figure 1. Effect of extract on cholesterol level of dyslipidemic rats. All values are expressed as Mean $\pm \mathrm{SD}, \mathrm{n}=5$; $\# \mathrm{p}<0.05$ compared to normal; * $p<0.05$ compared to positive control. The statistical calculation was performed using Anova.

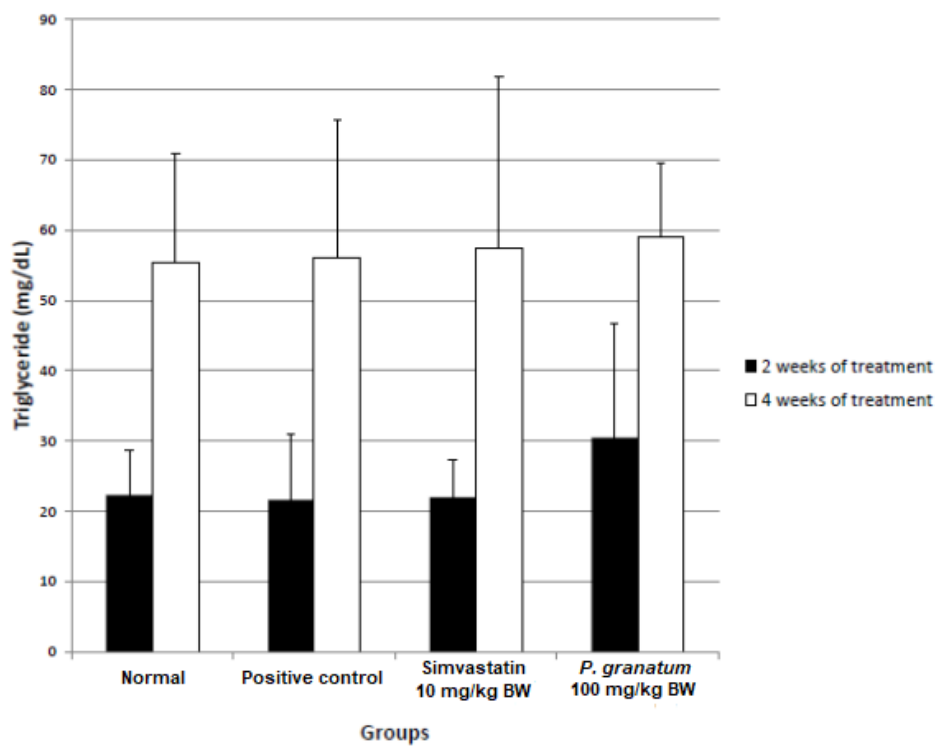

Figure 2. Effect of extract on triglyceride level of dyslipidemic rats. All values are expressed as Mean $\pm \mathrm{SD}, \mathrm{n}=5 ; \# \mathrm{p}<0.05$ compared to normal; * $p<0.05$ compared to positive control. The statistical calculation was performed using Anova.

it was put into $70 \%$ alcohol, alcohol $80 \%, 90 \%$ alcohol, 95\% alcohol, absolute alcohol, and xylol for 2 minutes each. The object glass cleaned for the remaining xylol and covered with a cover glass. Furthermore, the slide was observed under a microscope.

\section{Statistical Analysis}

ANOVA in SPSS 21.0 was used to analyze statistically significant differences between the control and the experimental groups. $p<0.05$ was considered to be statistically significant.

\section{RESULTS AND DISCUSSION}

At the beginning of induction of dyslipidemia, the average total cholesterol level of all the test groups was $78.4 \mathrm{mg} / \mathrm{dL}$ which were not statistical different among other groups (Figure 1). After 12 weeks of induction, the total cholesterol level of the dyslipidemic rats increased significantly compared to normal group (Figure 1). $P$. granatum leaf extract at dose of $100 \mathrm{mg} / \mathrm{kg}$ bw given for a month on dyslipidemic rat could reduce total cholesterol and LDL-cholesterol level. Unpublished 
data showed that an increase dose of the extract could increase its activity in reducing total cholesterol and LDL-cholesterol level.

In this study, the induction of dyslipidemia was performed exogenously for 3 months. The chow compositions for dyslipidemia induction were high cholesterol chow, $100 \mathrm{mg} / \mathrm{kg}$ bw pure cholesterol in vegetable oil, $200 \mathrm{mg} / \mathrm{kg}$ bw of cholic acid in vegetable oil, and propylthiouracil $12.5 \mathrm{mg} / \mathrm{kg}$ bw in aquadest. Cholic acid is one of the major bile acids in the body that was given to increase the absorption of exogenous cholesterol by inhibiting cholesterol conversion to bile acids (Hall, 2016). Meanwhile, propylthiouracil was given to inhibit metabolism of cholesterol, therefore it increased the levels of cholesterol serum (Rizos et al., 2011). In this study, we only used male rats as it has been shown in previous publication that there is no effect of gender in increasing of serum and hepatic cholesterol level upon cholesterol supplementation (Marounek et al., 2012).

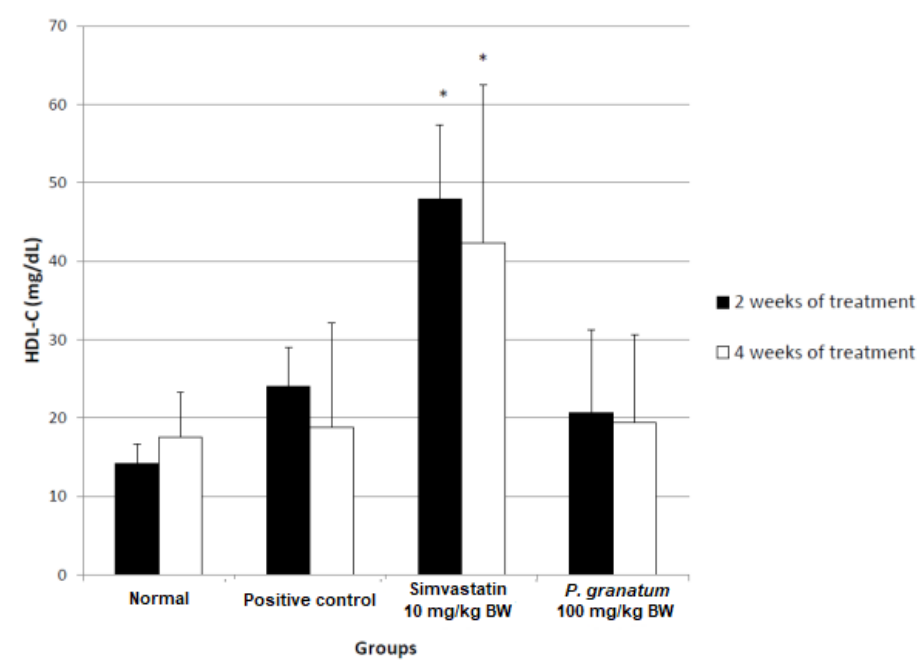

Figure 3. Effect of extract on HDL-cholesterol level of dyslipidemic rats. All values are expressed as Mean \pm SD, $n=5 ; \quad \# p<0.05$ compared to normal; * $p<0.05$ compared to positive control. The statistical calculation was performed using Anova.

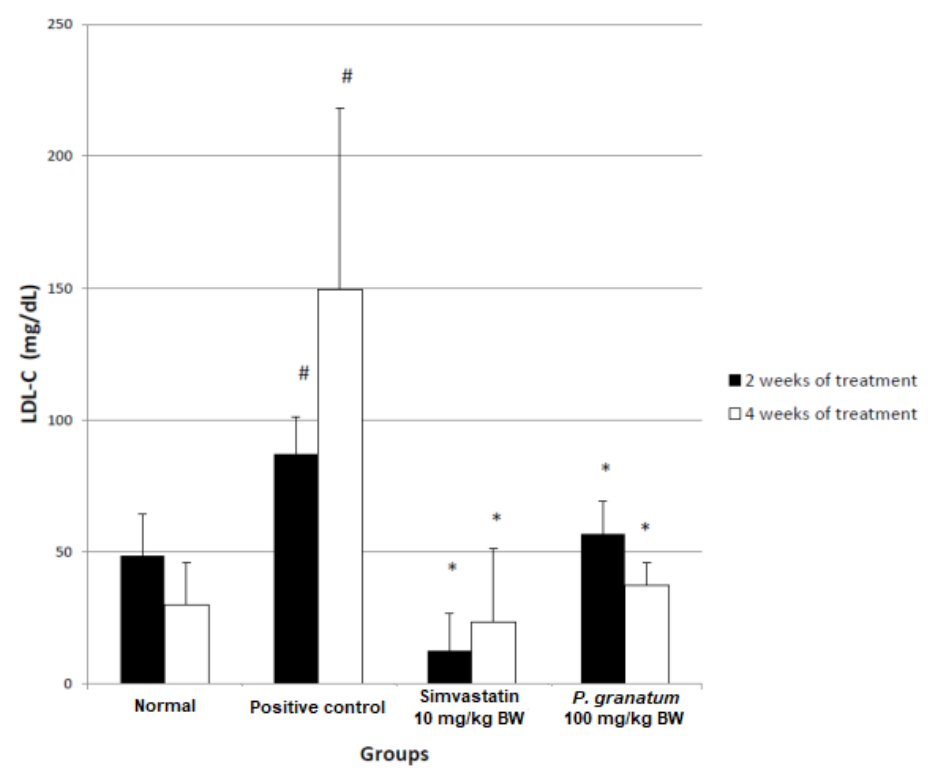

Figure 4. Effect of extract on LDL-cholesterol level of dyslipidemic rats. All values are expressed as Mean \pm SD, $n=5 ; \# p<0.05$ compared to normal; * $p<0.05$ compared to positive control. The statistical calculation was performed using Anova. 
Upon simvastatin treatment, it was found that simvastatin could reduce total cholesterol and LDL level significantly compared to positive control (Figure 1 and 4). Furthermore, it could increase HDL level significantly but had no effect on triglyceride level (Figure 2 and 3). Simillar to simvastatin, punica leaf extract treatment could reduce total cholesterol and LDL levels significantly compared to positive control after 2 and 4 weeks of treatment (Figure 1 and 4). However, it has no effect on triglyceride and HDL levels at any time of observation (Figure 2 and 3 ).

Histological study showed that high cholesterol induction exhibited a significant increased aortic wall thickness compared to normal group. In simvastatin and $P$. granatum leaf extract group, the treatments could reduce aortic wall thickness significantly compared to positive control (Figure 5).

The results of this study suggest that Punica granatum leaf extract has potential to be developed as antidyslipidemia drug. It has been reported before that Punica granatum leafhas antidyslipidemia effect, however the animal model used was alloxan or streptozotocin-induced non-insulindependent diabetes mellitus albino rats (Das \& Barman, 2012; Salwe et al., 2015). Alloxan and streptozotocin are known as a substance that can damage $\beta$-cell pancreas, leading to hyperglycemia. Although diabetic rats exhibit abnormalities in lipid metabolism as evidenced by the elevated levels of cholesterol, triglycerides, low-density lipoprotein cholesterol and very low-density lipoprotein, this model is not directly showed its effect on induction of dyslipidemia exogenously.

Besides the leaf, the antihyperlipidemia activity of the flower, fruit (aril and seed), and fruit peel of Punica granatum has also been studied (Abaas et al., 2014; Sadeghipour et al., 2014). All those parts of Punica granatum showed its activity in lowering the lipid profile. Compared to aril and seed, fruit peel of Punica granatum had better effect on lowering total cholesterol level (Mageid et al., 2016). It would be interesting to study further on its activity compared to leaf extract.

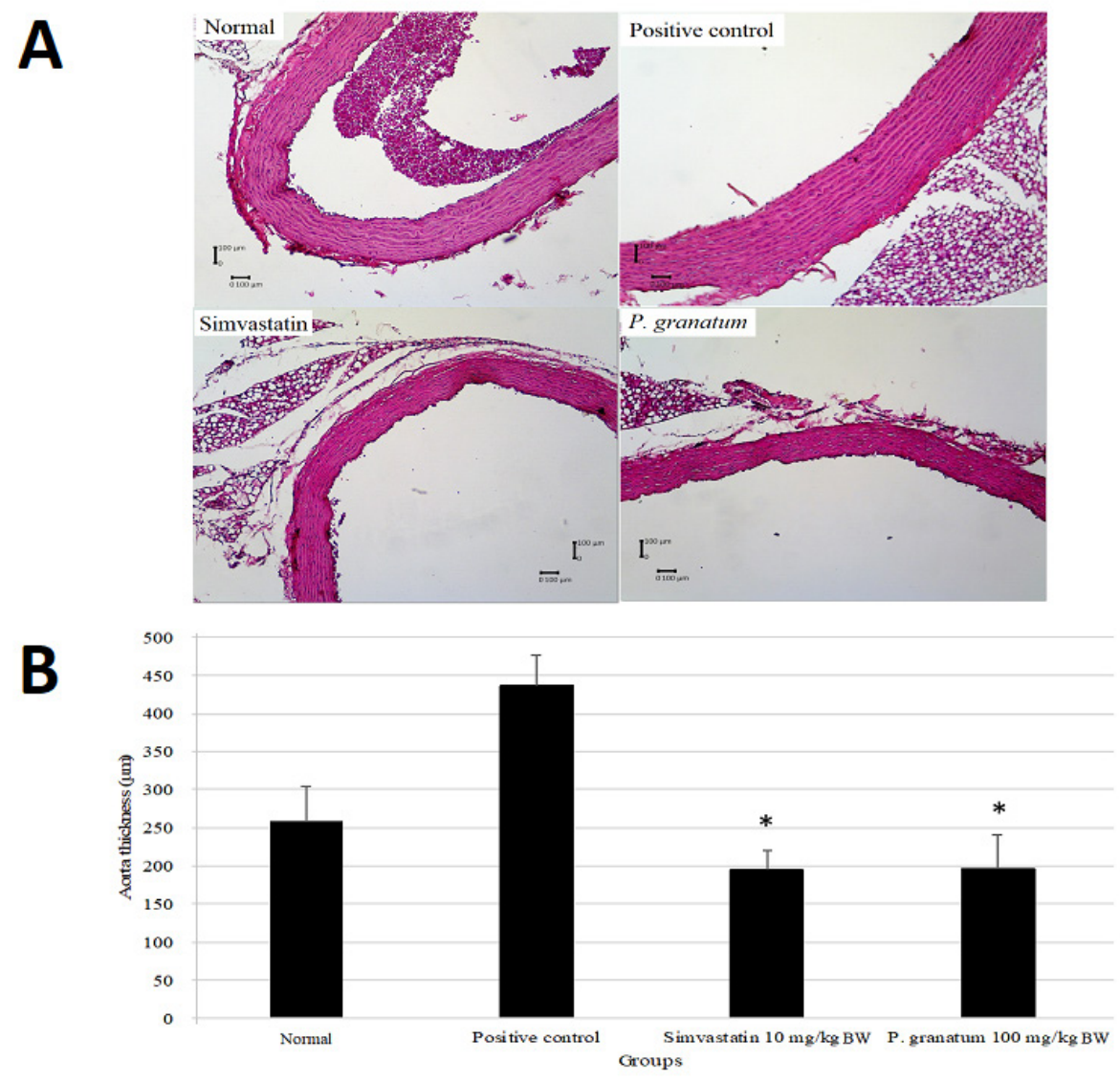

Figure 5. Histological examination of aortic hypertrophy in extract treated dyslipidemic rats. (A) Representative cross section of aortic wall stained with HE. Magnification 400x. (B) Bar graphs show the quantitative analysis of aortic wall thickness. $\mathbf{N}=3, * \mathrm{P}<0.05$ vs positive control. The statistical calculation was performed using Anova. 
Punica granatum fruits, seeds, and peels contain numerous valuable ingredients such as flavonoids, ellagitannin, punicalagin, ellagic acid, vitamins, and minerals (Jasuja et al., 2012). Punicalagins and ellagitannin have been reported to be responsible for immeasurable health benefits due to its strong antioxidant activity (Suo et al., 2009). Antioxidant has been reported to play a role in protecting from oxidative damage by reactive oxygen species, thus it might reduce the peroxidation rate and prevent the progressive disease due to dyslipidemic condition (Yang et al., 2008). Recent evidences showed that Punica granatum fruits, peels, and seeds can inhibit free radical effect and modulation of enzymes activity linked with diseases development and progression (Rahmani et al., 2017). P. granatum leaves contains tannins (punicalin and punicalagin), flavonoid glycosides (luteolin and apigenin) (Jurenka, 2008). Tannins are able to decrease cholesterol and triglyceride serum level in high-fat diet-induced obese mice (Lei et al., 2007). For futher research, it would be interesting to find the major component that play a role in antidyslipidemia effect.

\section{CONCLUSION}

This study demonstrated that pomegranate leaf extract at dose of $100 \mathrm{mg} / \mathrm{kg}$ bw rat has potential to be developed as antidyslipidemia drug as it can reduce total cholesterol and LDL-cholesterol level in hypercholesterolemia chow-induced dyslipidemic rat model.

\section{CONFLICT OF INTEREST}

The authors declare that they have no conflict of interest.

\section{ACKNOWLEDGMENT}

This study was supported by Ministry of Research, Technology and Higher Education of the Republic of Indonesia (PDUPT), 2018.

\section{REFERENCES}

Abaas, I., Hamzah, M., Ali, A.J. (2014). Extraction, identification, and antifungal studies of leaves extract of Punica granatum L. World Journal of Pharmacy and Pharmaceutical Sciences, 3(3), 190-202.

Abd El-Mageid, M. M., Salama, A. R., Saleh, M. A. M., \& Abo-Taleb, H. N. (2016). Evaluation of antidiabetic, hypocholesterolemic of pomegranate (Punica granatum L.) juice powders and peel powder extracts in male albino rats. IOSR Journal of Pharmacy and Biological Sciences, 11, 53-64.
Bhaskar, A., \& Kumar, A. (2012). Antihyperglycemic, antioxidant and hypolipidemic effect of Punica granatum L flower extract in streptozotocin induced diabetic rats. Asian Pacific Journal of Tropical Biomedicine, 2(3), S1764-S1769.

Das, S., \& Barman, S. (2012). Antidiabetic and antihyperlipidemic effects of ethanolic extract of leaves of Punica granatum in alloxan-induced non-insulindependent diabetes mellitus albino rats. Indian Journal of Pharmacology, 44(2), 219.

Esmaillzadeh, A., Tahbaz, F., Gaieni, I., Alavi-Majd, H., \& Azadbakht, L. (2004). Concentrated pomegranate juice improves lipid profiles in diabetic patients with hyperlipidemia. Journal of Medicinal Food, 7(3), 305308.

Hall JE, Guyton. (2016). Textbook of medical physiology (13 ${ }^{\text {th }}$ ed.). Philadelphia: Elsevier. 829.

Huang, T. H., Peng, G., Kota, B. P., Li, G. Q., Yamahara, J., Roufogalis, B. D., \& Li, Y. (2005). Anti-diabetic action of Punica granatum flower extract: activation of PPAR- $\gamma$ and identification of an active component. Toxicology and Applied Pharmacology, 207(2), 160169. doi: 10.1016/j.taap.2004.12.009

Jafri, M. A., Aslam, M., Javed, K., \& Singh, S. (2000). Effect of Punica granatum Linn.(flowers) on blood glucose level in normal and alloxan-induced diabetic rats. Journal of Ethnopharmacology, 70(3), 309-314.

Jasuja, N. D., Saxena, R., Chandra, S., \& Sharma, R. (2012). Pharmacological characterization and beneficial uses of Punica granatum. Asian Journal of Plant Sciences, 11(6), 251.

Jurenka, J. (2008). Therapeutic applications of pomegranate (Punica granatum L.): a review. Alternative Medicine Review, 13(2).

Kolovou, G. D., Anagnostopoulou, K. K., \& Cokkinos, D. V. (2005). Pathophysiology of dyslipidaemia in the metabolic syndrome. Postgraduate Medical Journal, 81(956), 358-366.

Lei, F., Zhang, X. N., Wang, W., Xing, D. M., Xie, W. D., Su, H., \& Du, L. J. (2007). Evidence of anti-obesity effects of the pomegranate leaf extract in high-fat diet induced obese mice. International Journal of Obesity, 31(6), 1023-1029.

Li, Y., Wen, S., Kota, B. P., Peng, G., Li, G. Q., Yamahara, J., \& Roufogalis, B. D. (2005). Punica granatum flower 
extract, a potent $\alpha$-glucosidase inhibitor, improves postprandial hyperglycemia in Zucker diabetic fatty rats. Journal of Ethnopharmacology, 99(2), 239-244.

Marounek, M., Volek, Z., Skřrivanová, E., \& Czauderna, M. (2012). Gender-based differences in the effect of dietary cholesterol in rats. Central European Journal of Biology, 7(6), 980-986.

National Institute of Health Research and Development, Ministry of Health, Republic of Indonesia (2013). Indonesia Basic Health Research, 258-260.

Nurfatwa M. (2016). Evaluasi ekspresi myeloperoksidase dan CD68 pada aorta dan jantung tikus hiperkolesterolemia [thesis]. Bandung: Sekolah Farmasi ITB

Patel, A. N., Bandawane, D. D., \& Mhetre, N. K. (2014). Pomegranate (Punica granatum Linn.) leaves attenuate disturbed glucose homeostasis and hyperglycemia mediated hyperlipidemia and oxidative stress in streptozotocin induced diabetic rats. European Journal of Integrative Medicine, 6(3), 307-321.

PERKI. (2013). Pedoman tatalaksana dislipidemia. 1st ed. Jakarta: Centa Communications. 1-2.

Rahmani, A. H., Alsahli, M. A., \& Almatroodi, S. A. (2017). Active constituents of pomegranates (Punica granatum) as potential candidates in the management of health through modulation of biological activities. Pharmacognosy Journal, 9(5).

Rizos, C. V., Elisaf, M. S., \& Liberopoulos, E. N. (2011). Effects of thyroid dysfunction on lipid profile. The Open Cardiovascular Medicine Journal, 5, 76.
Sadeghipour, A., Eidi, M., Ilchizadeh Kavgani, A., Ghahramani, R., Shahabzadeh, S., \& Anissian, A. (2014). Lipid lowering effect of Punica granatum L. peel in high lipid diet fed male rats. Evidence-Based Complementary and Alternative Medicine, 2014. doi: $10.1155 / 2014 / 432650$

Safitri, D., Kurniati, N. F., Adharani, S., Suciyati, S. W., \& Adnyana, I. K. (2016). The study of red ginger rhizomes ethanol extract (zingiber officinale roscoe var. Sunti val.) on hyperlipidemic-induced rats. Pharmacologyonline, 3, 15-21.

Salwe, K. J., Sachdev, D. O., Bahurupi, Y., \& Kumarappan, M. (2015). Evaluation of antidiabetic, hypolipedimic and antioxidant activity of hydroalcoholic extract of leaves and fruit peel of Punica granatum in male Wistar albino rats. Journal of Natural Science, Biology, and Medicine, 6(1), 56.

Sukandar, E. Y., Safitri, D. E. W. I., \& Aini, N. N. (2016). The study of ethanolic extract of binahong leaves (Anredera cordifolia [Ten.] Steenis) and mulberry leaves (Morus nigra L.) in combination on hyperlipidemicinduced rats. Asian Journal of Pharmaceutical and Clinical Research, 9(6), 288-98.

Suo, J. L., Peng, Y., Zhang, Z. Y., \& Wang, M. L. (2009). Studies on the optimum extraction and antioxidative activity of total flavonoids from Punica granaturn leaves. Biotechnology, 19, 63-65.

Yang, R. L., Shi, Y. H., Hao, G., Li, W., \& Le, G. W. (2008). Increasing oxidative stress with progressive hyperlipidemia in human: relation between malondialdehyde and atherogenic index. Journal of Clinical Biochemistry and Nutrition, 43(3), 154-158. 